\title{
Gestão de resíduos sólidos urbanos em Guarapuava-Paraná
}

\author{
Management of solid urban in Guarapuava Parana
}

\author{
Marcos Henrique Pazini'(*) \\ Silvio Roberto Stefano \\ Arildo Ferreira $^{3}$ \\ Lisandro Pezzi Schmidt ${ }^{4}$
}

\section{Resumo}

Este trabalho teve como objetivo principal compreender o modelo de gestão de resíduos sólidos no município de Guarapuava-PR. Para isso foi realizado estudo na Secretaria de Meio Ambiente da prefeitura, sendo realizada uma pesquisa de campo com a equipe multidisciplinar que atua na gestão de resíduos sólidos urbanos com o uso de entrevistas individuais, diário de campo, análise documental, por meio das quais pôde-se verificar de que forma ocorre essa gestão, o modelo adotado atualmente e a efetividade desse modelo de gestão. Verificou-se que todos os entrevistados conhecem a temática, pois atuam com base na legislação e procuram desenvolver ações com cunho sustentável, promovendo o aculturamento da sociedade, quebrando paradigmas que envolvem a sustentabilidade e o desenvolvimento sustentável de toda cadeia produtiva onde a gestão de resíduos sólidos está inserida. Observam-se diversas ações sendo desenvolvidas, abrangendo todas as idades e camadas da sociedade local, bem como investimentos que promovam essa mudança de cultura, sendo essa a principal barreira para que a gestão de resíduos sólidos alcance melhores patamares ou índices de desenvolvimento.

Palavras-chave: sustentabilidade, desenvolvimento sustentável e gestão de resíduos sólidos

\section{Abstract}

The main objective this paper was to understand the solid waste management model in city of Guarapuava-PR. For this purpose, a study was carried out at the city's Environment Secretariat, and a field research was carried out with the multidisciplinary team that works in the management of solid urban waste using individual interviews,

1 Mestrando em Administração PPGADM; Universidade Estadual do Centro-Oeste, UNICENTRO, Brasil; Técnico Bancário Novo da Caixa Econômica Federal; Endereço: Caixa Econômica Federal. Rua Floriano Peixoto, 1515, Centro. CEP: 85010100 - Guarapuava, PR - Brasil; E-mail: mhpazini@hotmail.com (*)Autor para correspondências

2 Dr.; Administração; Universidade de São Paulo, USP, Brasil; Professor Associado da Universidade Estadual do CentroOeste UNICENTRO; Endereço: Universidade Estadual do Centro-Oeste, Deadm. Rua Padre Salvador Renna, 875, Santa Cruz.85015-430 - Guarapuava, PR - Brasil; E-mail: professor-silvio@hotmail.com

3 Dr.; Administração; Universidade do Vale do Itajaí, UNIVALI, Brasil; Professor do Departamento de Administração da Universidade Estadual do Centro Oeste; Endereço: niversidade Estadual do Centro Oeste, UNICENTRO. Rua Presidente Zacarias, 875, Santa Cruz. CEP: 85015-430 - Guarapuava, PR - Brasil; E-mail: arildo@unicentro.br

4 Dr.; Geografia; Universidade Federal de Santa Catarina, UFSC, Brasil; Chefia do Departamento de Geografia, Guarapuava-PR; Endereço: Universidade Estadual do Centro-Oeste, Centro de Ciências Agrárias e Ambientais, Departamento de Geografia. Rua Simeão Camargo Varela de Sá, 03, Vila Carli. 85040-080 - Guarapuava, PR - Brasil; E-mail: lisandrops@hotmail.com

Recebido para publicação em 31/0I/20I7 e aceito em 23/05/2019

\begin{tabular}{llllll}
\hline Ambiência & Guarapuava (PR) & v.I5 n.I & p.94 - III & Jan/Abr 2019 & ISSN I808 - 025I
\end{tabular}


field diary, documentary analysis, through which it was possible to verify in what form this management takes place, the model adopted today and the effectiveness of this management model. It was verified that all interviewees know the theme, act on the basis of legislation and seek to develop sustainable actions, promoting the acculturation of society, breaking paradigms that involve the sustainability and sustainable development of the entire productive chain where solid waste management It's inserted. A number of actions are being carried out, covering all ages and strata of local society, as well as investments that promote this change of culture, which is the main barrier for solid waste management to reach better levels or indices of development.

Keywords: sustainability, sustainable development and solid waste management

\section{Introdução}

A Política Nacional de Resíduos Sólidos, com foco na gestão integrada e sustentável de resíduos sólidos, vem estimulando discussões para a construção de conhecimento científico e fomentando um processo de mudança direcionado para um novo modelo de desenvolvimento humano e socioambiental. Nessa perspectiva, os gestores devem tomar suas decisões pautados não somente nas atuais exigências legais, mas, principalmente, na busca pelo desenvolvimento sustentável (VEIGA, 2014, p.10).

Diversas organizações voltaram-se para a ciência da responsabilidade social, de proteger o clima global, ao mesmo tempo em que buscam ou tentam colher benefícios econômicos e até mesmo estratégicos (HOFFMAN, 2004). Como tal, a temática da gestão ambiental surgiu na década de 1960 (FERREIRA, 2018, p.106). Já a origem do conceito do desenvolvimento sustentável remonta à Conferência da ONU em Estocolmo, em 1972, porém o tema ganhou abrangência mundial apenas na RIO-92 (STEFANO; TEIXEIRA, 2014).

Vistos a partir da ótica ambiental e econômica, os desafios globais associados à sustentabilidade podem ajudar a identificar estratégias e práticas que contribuam para um mundo mais sustentável (HART; MILSTEIN, 2004, p. 68).

Sachs (2008) ressalta que as empresas, independentemente do tamanho, não devem apenas focar no lucro. Um empresário, quando inicia alguma atividade, foca no lucro e, o faz tendo-o como única motivação, pois, segundo ele, o lucro é a via pela qual conseguirá estruturar melhor a sua empresa, fornecendo melhores condições de trabalho, melhores salários e, consequentemente, permitirá reter talentos.

Na mesma linha, Elkington (2001) argumenta que a preocupação do lucro deve estar alinhada à preservação ambiental e fazer com que a gerência das organizações sofra desafios constantes, tendo em vista que não basta mais agradar somente o seu cliente com a oferta de produtos e serviços acessíveis, visando à lucratividade. Outros aspectos devem ser considerados, como os impactos ambientais resultantes das atividades produtivas e a questão social vinculada às atividades empresariais. Nesse sentido, Jonh Elkington (2001) desenvolveu o conceito de expansão das atividades empresariais, ao que denominou Triple Botton Line (TBL) - Tripé da Sustentabilidade, ou seja, esse conceito considera que para o sucesso empresarial, a gestão da empresa deve integrar as diferentes dimensões- econômica, social e política- visando à competitividade e sustentação no século 21 (ELKINGTON, 2001). 
Desse modo, como exemplo de utilização dos aspectos legais e no intuito de identificar os fatores do TBL na Gestão de Resíduos Sólidos Urbanos, delimitou-se o estudo à Secretaria do Meio Ambiente do Município de Guarapuava, que se localiza na Mesorregião Centro-Sul do Estado do Paraná, sendo a cidade mais populosa, com aproximadamente 180 mil habitantes (IBGE, 2010). Dessa forma, este artigo teve como objetivo principal compreender o modelo de gestão de resíduos sólidos no município e seus aspectos positivos e limitadores.

A Lei 12.305 de 02/08/2010 (BRASIL, 2010), que institui a política nacional de Resíduos Sólidos, impôs diversos desafios para a esfera municipal na gestão de resíduos de sólidos urbanos, o que justifica a análise do modelo municipal proposto neste estudo.

O presente estudo está dividido em análise teórica, que fundamenta a sustentabilidade com a gestão dos resíduos sólidos urbanos, bem como a fundamentação legal específica do tema. Pela análise de resultados, que trata da pesquisa de campo, procurou-se entender o modelo de gestão de resíduos sólidos urbanos praticado no município de Guarapuava-PR: como a equipe responsável por essa gestão está inserida no tema, pode-se conhecer os problemas que a cidade enfrenta, que atividades desempenham e quais vantagens essa gestão implantou para a melhoria da gestão dos resíduos sólidos urbanos no município.

\section{Referencial Teórico}

\section{Desenvolvimento Sustentável e Sustentabilidade}

Somente após a virada do século XX, o tema desenvolvimento sustentável se ligou intimamente a assuntos organizacionais, pois fala-se em impactos ambientais, administração de recursos naturais, bem como impacto do homem moderno num contexto mais amplo da sociedade.

Para Sachs (2008), desenvolvimento sustentável é a utilização dos recursos naturais visando atender a sociedade com produtos e serviços sem prejudicar as gerações futuras. Todavia, o mesmo autor afirma que a transição para o desenvolvimento sustentável requer uma mudança de paradigma para o gerenciamento de crise.

Sob essa ótica de pensamento, Hopwood, et al (2005) conceituam o desenvolvimento sustentável como o resultado da crescente consciência dos elos globais entre a montagem dos problemas ambientais, questões socioeconômicas a ver com a pobreza e a desigualdade e as preocupações sobre um futuro saudável para a humanidade.

O desenvolvimento sustentável é um processo de realização de desenvolvimento de forma inclusiva, conectada e equitativa (GLADWIN, et al, 1995), uma vez que é necessário que todos que fazem parte do processo interajam de forma igualitária, para a socialização dos benefícios; como exemplo, ao investir em educação, promove-se um crescimento da escolaridade da população, melhorando a cultura e gerando pessoas mais cidadãs, com uma visão mais no coletivo, e não no individualismo. Consequentemente, no final, tudo isso gerará mais qualidade de vida e um desenvolvimento mais sustentável em todos os aspectos.

Os cincos pilares do desenvolvimento sustentável são (SACHS, 2008):

a) Social fundamental por motivos tanto intrínsecos quanto instrumentais, por causa da perspectiva de disrupção social que paira de forma ameaçadora sobre muitos lugares problemáticos do nosso planeta; 
b) Ambiental, - com as suas duas dimensões (os sistemas de sustentação da vida como provedores de recursos e como "recipientes" para a disposição de resíduos);

c) Territorial - relacionado à distribuição espacial dos recursos, das populações e das atividades;

d) Econômico - sendo a viabilidade econômica "a conditio sine qua non" para que as coisas aconteçam;

e) Político - a governança democrática é um valor fundador e um instrumento necessário para fazer as coisas acontecerem, a liberdade faz toda a diferença.

Para Hopwoodet al. (2005, p.40), é insustentável a produção de resíduos através do modelo de crescimento econômico atual. Deve-se agir entendendo que os recursos são finitos, repensando o modelo de capitalismo atual, mudando o foco de apenas crescimento econômico para o uso de recursos de maneira consciente, produtiva e eficaz.

Ressalta-se que há várias interpretações sobre desenvolvimento sustentável e que muitas são confusas (HOPWOOD et al,2005). Os mesmos autores enfatizam que há linhas ou mapeamentos de pensamentos que vão do ecocentrismo para o tecnocentrismo, sendo que o ecocentrismo tende para a equidade social, econômico e redistribuição, enquanto o tecnocentrismo é mais propenso a apoiar o status quo econômico e político.

Aprofundando sobre o paradoxo ecocentrismo e tecnocentrismo, Gladwin et al (1995) distinguem que,

Tecnocentrismo- desassocia a economia humana da natureza não humana; possui visão fraturada do mundo, separando pensamentos, valores e fatos, espírito e matéria, sendo uma lógica de subdesenvolvimento, podendo perpetuar e aprofundar disparidades econômicas e sociais.

Ecocentrismo - tende a ser evidente nos sistemas de crenças dos direitos, nas quais tudo está ligado à terra; o bem-estar humano é um derivado da função ativa, secundário ao bem-estar da Terra, onde o crescimento material aumenta os custos ambientais e sociais.

Gladwin et al (1995) abordam que a sustentabilidade exige uma compreensão dos problemas do mundo como sistematicamente interconectados e interdependentes, e que o desenvolvimento é baseado no reconhecimento de que uma nação não pode alcançar objetivos econômicos sem atingir objetivos sociais e ambientais. Reforça ainda que, nem o tecnocentrismo, nem o ecocentrismo aparecem para oferecer uma base sobre a qual o desenvolvimento sustentável pode ser alcançado.

Savitze e Weber (2013) afirmam ainda que a maioria das empresas que buscam a sustentabilidade o fazem porque enxergam um forte argumento comercial para isso. Ao mesmo tempo, o movimento em direção à sustentabilidade também pode fortalecer a lealdade, motivação e comprometimento dos trabalhadores. No entanto, muito poucos líderes empresariais pensam em sustentabilidade em termos de aumentar o engajamento dos funcionários.

Pela afirmação anterior de Gladwin et al (1995), eles evidenciam uma terceira vertente ou paradigma do desenvolvimento sustentável, chamado de "sustaincentrismo". Essa vertente representa uma síntese emergente que busca uma integração homem e recursos naturais mais alta e mais intensa.

As tecnologias e o emprego destas devem ser desenvolvidas de forma apropriada, justa e humana, pois os problemas são graves e urgentes. O paradigma sustentado aceita que material, energia e o crescimento são cerceados por limites ecológicos e entrópicos; o crescimento não 
pode ir sempre em um sistema fechado. O paradigma sustentado permite os interesses de hoje e de amanhã, de ricos e pobres, de Norte e Sul para adquirir um desenvolvimento mais completo e uma atenção mais profunda (GLADWIN et al, 1995, p.893-895).

Contudo, ao verificar toda a conceituação sobre desenvolvimento sustentável, quais ferramentas são necessárias para o desenvolvimento dessa teoria? Como mensurar o que está sendo feito na sociedade e nas organizações, condiz com uma sustentabilidade moderna, preocupada com as pessoas, com o ambiente e com as organizações?

É relevante a visão de Sachs (2008) segundo a qual, para se conseguir um desenvolvimento sustentável, o emprego decente para toda a população deve ser imprescindível e, para que isso ocorra, todas as medidas possíveis devem ser tomadas, pois o trabalho é um fim e, também, um meio. É importante não apenas pelo rendimento material que proporciona, mas porque dá ao indivíduo um sentido de identidade, a consciência de ter um objetivo na vida social, a sensação de estar integrado numa sociedade. O trabalho é essencial à qualidade de vida, quer as pessoas sejam empregadas por conta de outra, ou trabalhem para si próprias; o trabalho traz os alimentos, o vestuário e a habitação, ou fornece o rendimento que permite comprá-los. O trabalho é o principal meio pelo qual as pessoas tentam satisfazer as suas necessidades de qualidade de vida: um padrão de vida decente, alimentos suficientes, habitação digna, água potável, saneamento e lazer.

Sob tal ótica, vale ressaltar que o progresso econômico passa por desafios como: oportunidades de trabalho digno, remuneração e geração de riqueza. Uma das formas ou ações que valorizam o desenvolvimento de uma região são os chamados APL - arranjos produtivos locais, os quais fortalecem um determinado segmento, agregando valor e renda na atividade produtiva. Outra forma de melhorar o desenvolvimento sustentável, e nesse ponto é importante e se faz necessário o papel do ente público, são linhas de créditos com juros e condições que propiciem melhoria da infraestrutura dos pequenos empreendedores, gerem emprego com salários dignos e que, consequentemente, agreguem valor, gerando riqueza.

Outra situação de destaque sobre o desenvolvimento sustentável é que, segundo Sachs (2008), os países em desenvolvimento, em especial o Brasil, deveriam transformar-se em uma fábrica de empregos. Contudo a realidade é bem diferente. $\mathrm{O}$ autor enaltece o setor do agronegócio, com uma indústria moderna e diversificada, porém peca demasiadamente na qualidade da infraestrutura, onde se reflete o atraso social. O Brasil, pelas proporções que tem, poderia utilizar todas as espécies de modais para escoar não somente a safra de grãos, mas também qualquer forma de produto e serviços.

Outro ponto bastante pertinente e que Sachs (2008) defende é a reforma agrária, todavia, antes de se realizar uma reforma agrária organizada, é preciso mudar a cultura de uma nação; porém, há a sensação, ou é visualizado, que boa parte das pessoas que estão inseridas no pleito pela conquista de um pedaço de terra já foi beneficiada pelo programa, evidenciando corrupção do sistema.

Todavia, Hoffman (2004, p. 6) afirma que, na sustentabilidade há grandes oportunidades. Existem aqueles com interesse em resistir e tentando atrasar tal transformação de mercado, e aqueles que tentarão aproveitar e capitalizar essas oportunidades. A diferença entre esses dois grupos está em uma análise cuidadosa de custo/benefício de fazer algo contra o de nada fazer.

Sob tal ótica, Blowfield (2013) pondera que a sustentabilidade é um termo relativamente novo. Seu primeiro uso, registrado em um contexto ambiental, foi em 1980; porém o conceito do ambiente como a soma total das condições externas à vida remonta ao século XIX, talvez substituindo a "economia da natureza", que já foi usado desde o século XVII para se referir ao mundo natural como um todo. 
Sachs (2008) afirma que pequenos empreendedores buscam a competitividade oferecendo baixos salários aos trabalhadores. Tendo a discordar de tal ponderação, visto que ao analisar a conjuntura atual observa-se que várias empresas, start-ups e empreendimentos são formados por jovens com elevado grau de escolaridade, sendo que esses jovens empresários buscam não somente o retorno sobre o investimento, mas também a realização de um sonho, de proporcionar um benefício para sociedade de consumo, gerando renda e riqueza.

A fim de discorrer sobre o tema Sustentabilidade Organizacional, primeiramente é necessário buscar entender o contexto em que está inserida sobre o arquétipo da teoria da sustentabilidade, ou seja, buscar uma revisão da literatura sobre desenvolvimento sustentável, sustentabilidade e sustentabilidade organizacional (MUNCK, et al, 1995).

Já, a respeito de uma visão mais ampla sobre o surgimento do conceito de sustentabilidade, Munck (2014) ressalta que esse conceito originou-se com biólogos e ecologistas, que o usaram para descrever as taxas dentro das quais os recursos renováveis podem ser extraídos ou danificados pela poluição, sem ameaçar a integridade dos ecossistemas subjacentes.

Entretanto, de forma pragmática, Elkington (2012,p.92) define que, para uma sociedade ser sustentável, a mesma precisa atender a três condições: suas taxas de utilização de recursos renováveis não devem exceder suas taxas de regeneração; suas taxas de uso de recursos não renováveis não devem exceder a taxa pela qual a renovação sustentável dos substitutos é desenvolvida; suas taxas de emissão de poluentes não devem exceder a capacidade de assimilação do meio ambiente.

Enquanto a sustentabilidade representa um argumento inquestionável, pois independe de seu objetivo final, o desenvolvimento sustentável é entendido como um conjunto de ações de inclusão, integração, igualdade, prudência e segurança, ou seja, o desenvolvimento sustentável deve ser considerado como um caminho para a sustentabilidade (MUNCK, et al, 2013).

O Desenvolvimento Sustentável chegou ao setor empresarial com maior afinco por volta da década de 1990. Desde então, as discussões de temas ambientais, sociais e econômicos no cenário organizacional centram-se, primordialmente, na releitura de reincorporação de conceitos e na redefinição de paradigmas de gestão (MUNCK, 2014, p. 7). Conforme ainda mencionam os autores, as empresas, naturalmente, buscam maneiras de melhorar desempenho e lucro, sendo que ainda é um desafio integrar preocupações sociais e ambientais aos processos organizacionais e que ainda é um paradoxo lidar, simultaneamente à excelência social, com o financeiro nas organizações. Afirmam, complementarmente que há várias ferramentas de mensuração da sustentabilidade organizacional que estão sendo desenvolvidas e aperfeiçoadas, e que algumas premissas já estão vinculadas ao contexto das organizações, como: redução de custos pela utilização de métodos de produção mais limpos e inovadores; menores custos relacionados à saúde e segurança; menores e inovadores custos trabalhistas; as melhores práticas influenciam as legislações, a reputação organizacional e a vantagem mercadológica.

Sob tal ótica Blowfield (2013, p. 53) afirma que

As empresas já estão se adaptando à restrição de recursos à medida que os esquemas de comércio de emissões são implementados em mais e mais indústrias, e os subsídios ao petróleo são removidos. A mudança climática está afetando a indústria agro-alimentar, criando novas incertezas e especulações. O estresse hídrico também é uma ameaça para a indústria, não apenas em termos de produção, mas também o impacto em sua reputação, uma vez que é acusado de ser devido ao esgotamento da água e aos altos preços dos alimentos. Em indústrias de aviação a automotivas, serviços públicos a fast-food, há conscientização sobre como os diferentes desafios de sustentabilidade afetam o sucesso dos negócios e, em muitos casos, isso leva as empresas a participar de iniciativas relacionadas à sustentabilidade. 
De fato, não há uma definição única ou consensual para a- sustentabilidade organizacional (SO), porém inúmeros autores convergem para uma ideia básica de que a sustentabilidade organizacional está interligada em três pilares: o pilar econômico, o ambiental e o social. Assim sendo, sustentabilidade organizacional pode ser definida como o encontro das necessidades de stakeholders diretos e indiretos, sem que a capacidade de sustentar necessidades futuras seja comprometida (MUNCK, 2014).

Ressalta-se que a iniciativa privada é vivamente elogiada como uma solução para as dificuldades da sociedade em alcançar a sustentabilidade, e culpada como a geradora de nossos problemas. Mas, independentemente de o negócio ser considerado um salvador ou um pecador, a maior parte do que as empresas estão fazendo, sob um guarda-chuva de sustentabilidade, está conectada à inovação e eficiência (BLOWFIELD, 2013).

Através da inovação e da eficiência da abordagem da sustentabilidade, dos processos que englobam o desenvolvimento sustentável e, por fim, que permeiam a sustentabilidade organizacional, geraram-se vários modelos de gestão, como (MUNCK, 2014):

a) Sistema de Gestão da SO - SGSO: alcançar a SO não é uma tarefa trivial, envolve visão, comprometimento e liderança;

b) Rede Corporativa Sustentável Local - SLEN: tem por finalidade descrever a maneira pela qual as iniciativas sustentáveis ocorreram em países em desenvolvimento;

c) Balanced Scorecard Hexagonal - BSH: nesse modelo, Munck (2014, p. 43) afirma que há uma integração do BSC - balanced scorecard e o mapa estratégico de Kaplan e Norton (1996, 2000), sistemas internos de gestão que contêm medidas de resultado em quatro perspectivas: financeira, cliente, processos internos e aprendizado e crescimento.

d) Síntese Socioeconômica - SSE: esse modelo propõe soluções práticas que combinem alta competitividade e desempenho econômico com ótimos desempenhos sociais e ambientais;

e) Framework: esse modelo contempla um agir organizacional processual capaz de qualificar, categorizar, conduzir os preceitos da sustentabilidade em contexto organizacional.

Contudo, de acordo com Blowfield (2013), o negócio é um elemento muito importante para enfrentar os desafios de sustentabilidade do mundo, mas a natureza dos desafios significa que o pensamento empresarial convencional não tem a garantia de funcionar. Cabendo apenas ideias estabelecidas sobre estratégia corporativa.

Um ponto bastante interessante sobre a teoria da sustentabilidade, desenvolvimento sustentável e sustentabilidade organizacional, é o fato de os autores abordarem contextos históricos que marcaram a história humana e como tais aspectos impactaram na sociedade.

\section{Gestão de Resíduos Sólidos}

Nas últimas cinco décadas, tem ocorrido uma significativa mudança no ambiente em que as empresas operam: as empresas que eram vistas apenas como instituições econômicas com responsabilidades referentes a resolver problemas econômicos fundamentais têm presenciado o surgimento de novos papéis que devem ser desempenhados, como resultado das alterações no ambiente em que operam (DONAIRE, 2013, p.13). 
Donaire (2013) afirma que essa mudança se baseia na assertiva de que, ao combinar o modelo do sistema capitalista, voltado para uma eficaz administração de recursos, com ciência e tecnologia, e o confrontando com resultados sociais, percebe-se que há muito a ser conseguido e que apenas o crescimento do PNB - Produto Nacional Bruto não basta para avaliar a performance social.

Corroborando com a matriz (figura 1) de Hart e Milstein (2004, p.68), sobre o eixo da "estratégia: combate à poluição", a problemática dos resíduos sólidos somente passou efetivamente a integrar a agenda governamental a partir do século XX, mais precisamente entre as décadas de 1940 e 1970 (NETO, 2013, p.1).

\section{Figura 1 - Matriz de modelo de valor sustentável}

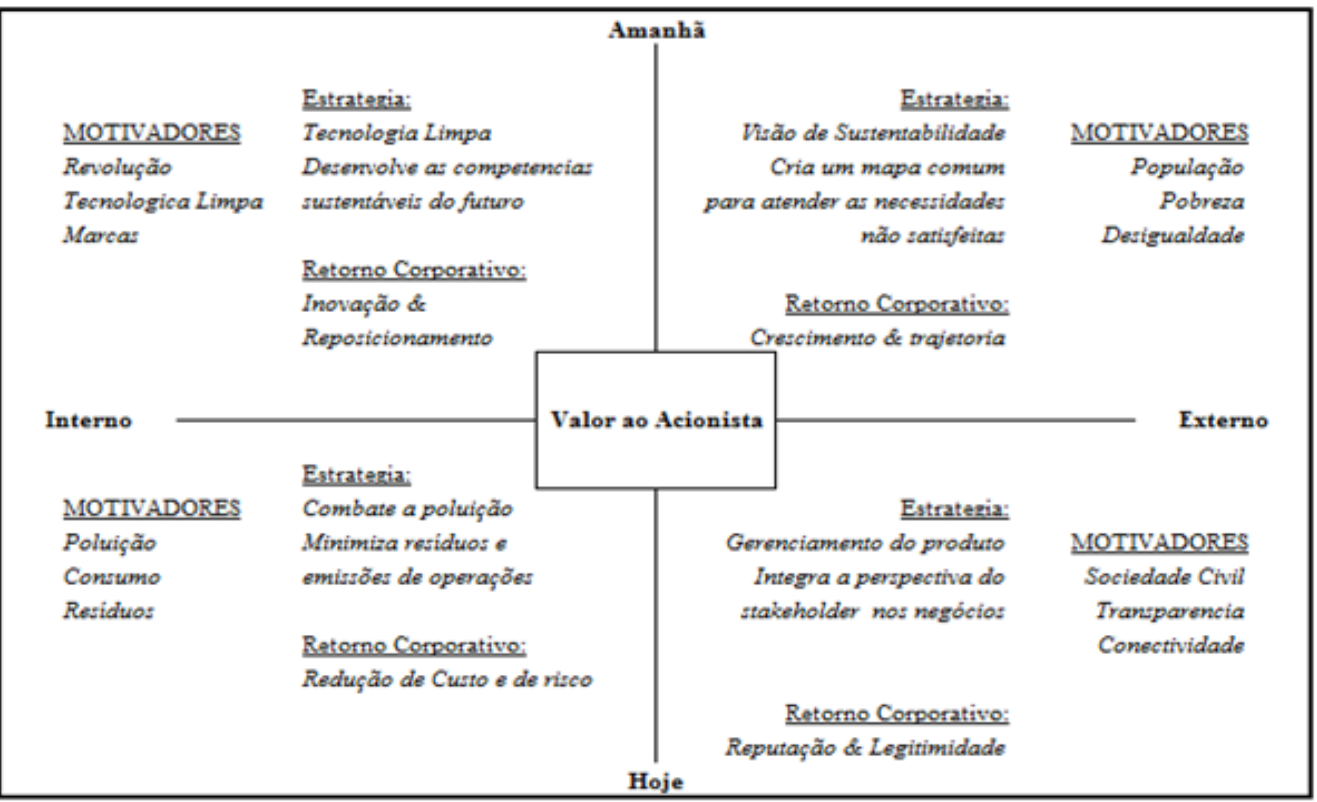

Fonte: Hart e Milstein (2004, p. 71).

De fato, por meio da análise da matriz de Hart e Milstein (2004), o desenvolvimento sustentável configura-se em vantagem competitiva às organizações, onde ações e objetivos estratégicos podem angariar novos mercados, novos clientes e, logicamente, aumento da lucratividade de maneira sustentável.

De acordo com a Lei no 12305/2010, que trata da Política Nacional de Resíduos Sólidos, estes são definidos como os materiais ou substâncias em estado sólido ou semissólido, resultantes de atividades humanas que são descartados e necessitam destinação final adequada, escolhida em face da sua natureza e da tecnologia disponível. De acordo com Neto (2013), percebe-se um claro alinhamento conceitual da Lei n 12.305 com a Agenda 21, NBR 10.004/2004 e com a legislação norte-americana.

A Lei 12.305/2010 também perfila, ao lado de outras leis ambientais no Brasil, como a Lei de Saneamento Básico, no 11455/2007, a Lei dos Consórcios Públicos, no 11.107/2005, a Política Nacional de Educação ambiental, no 9.795/1999, a Lei de Crimes Ambientais, no 9.605/1998, a Política Nacional de Recursos Hídricos, no 9.433/1997, a Lei da Política Nacional do Meio Ambiente, no 6.938/1981, assim como diversos artigos da Constituição Federal (Veiga, 2014, p.51). 
De acordo com o artigo 13, da Lei Federal n. 12.305 (BRASIL, 2010b), os resíduos sólidos se classificam quanto a sua origem e periculosidade. Em relação a sua origem, apresenta-se da seguinte maneira:

a) resíduos domiciliares: originários de atividades domésticas em residências urbanas;

b) resíduos de limpeza urbana: originários da varrição, limpeza de logradouros e vias públicas e outros serviços de limpeza urbana;

c) resíduos sólidos urbanos: englobados nas alíneas "a" e "b";

d) resíduos de estabelecimentos comerciais e prestadores de serviços: gerados nessas atividades, excetuados os referidos nas alíneas "b", “e”, "g”, "h" e “j”;

e) resíduos dos serviços públicos de saneamento básico: gerados nessas atividades, excetuados os referidos na alínea "c";

f) resíduos industriais: gerados nos processos produtivos e instalações industriais;

g) resíduos de serviços de saúde: gerados nos serviços de saúde, conforme definido em regulamento, ou em normas estabelecidas pelos órgãos do Sistema Nacional do Meio Ambiente (Sisnama) e da Secretaria Nacional de Vigilância Sanitária (SNVS);

h) resíduos da construção civil: gerados em construções, reformas, reparos e demolições de obras de construções civis, inclusive resultantes da preparação e escavação de terrenos para obras civis;

i) resíduos agrossilvopastoris: gerados nas atividades agropecuárias e silviculturais, incluídos os relacionados a insumos utilizados nessas atividades;

j) resíduos de serviços de transportes: originários de portos, aeroportos, terminais alfandegários, rodoviários e ferroviários e passagens de fronteira;

k)resíduos de mineração: gerados na atividade de pesquisa, extração ou beneficiamento de minérios; [...]. (BRASIL, 2010).

Ressalta-se que o desenvolvimento tanto da teoria da sustentabilidade quanto do desenvolvimento sustentável corroboraram para o pensamento da gestão de resíduos sólidos, contudo, tal gestão só ganhou ênfase através da legalização dos procedimentos em que cada município deveria desempenhar e executar.

\section{Procedimentos Metodológicos}

O presente estudo foi desenvolvido na Secretaria de Meio Ambiente do município de Guarapuava-PR. A secretaria conta atualmente com aproximadamente 25 funcionários no seu quadro pessoal, sendo que 5 destes atuam exclusivamente na gestão de Resíduos Sólidos Urbanos.

Dessa forma, com o propósito de compreender o modelo de gestão de resíduos sólidos no município de Guarapuava-PR, adotou-se o modelo qualitativo de pesquisa, com fins descritivos. A pesquisa foi qualitativa, considerando o interesse em aprofundar o conhecimento sobre um caso especifico (DENZIN; LINCOLN, 2006, p.16). A pesquisa também possui caráter descritivo, pois segundo Prodanov (2013), esse tipo de pesquisa visa descrever as características de determinada população, fenômeno ou o estabelecimento e as relações entre as variáveis.

No estudo de caso, foram utilizadas 02 fontes de pesquisa: (a) entrevistas semiestruturadas e diário de campo e, (b) documentos e registros em arquivos. Foram entrevistados todos os colaboradores que atuam exclusivamente na gestão de resíduos sólidos urbanos vinculados à 
Secretaria de Meio Ambiente do município de Guarapuava-PR, os quais foram denominados por meio de letras maiúsculas do alfabeto de "A" a "E".

Os questionários possuem 11 perguntas abertas que foram aplicadas aos 5 funcionários, e 34 perguntas fechadas aplicadas diretamente ao coordenador (a) da gestão de resíduos sólidos urbanos do município de Guarapuava. As entrevistas ocorreram no mês de julho de 2018 e variaram de 40 a 90 minutos. Ressalta-se que os questionários foram adaptados de Ferreira (2018), Veiga (2014) e Oliveira (2017).

Os questionários estão embasados no pressuposto de Elkington (2012), em que as organizações sustentáveis estão ligadas pelo TBL, pois o pilar econômico, o pilar ambiental e o pilar social interagem, apoiando-se um no outro, sustentando fatores que favorecem a integração organizacional, a inserção social, a ecoeficiência e a justiça socioambiental.

\section{Análise de dados e Resultados}

Segundo Ferreira (2018, p.105), a partir de 2010, com a implantação da Política Nacional de Resíduos Sólidos (PNRS), através da Lei 12.305/10, está havendo no Brasil uma nova dinâmica na forma de condução da gestão de resíduos sólidos urbanos. A responsabilidade pela gestão, que antes era somente do município, passa a ser compartilhada com todos os atores envolvidos na manipulação de resíduos, desde a fabricação até a destinação final.

Ressaltando com o quadrante estratégico da matriz de Hart e Milstein (2004), e conforme Almada e Borges (2018, p. 428), o objetivo do modelo TBL é medir o desempenho financeiro, social e ambiental da empresa. Os resultados das avaliações dessas dimensões tendem a refletir os valores que a organização está construindo, ou destruindo. Desta forma, buscou-se identificar, nesta pesquisa, o perfil dos agentes que atuam exclusivamente com a Gestão de Resíduos Sólidos na Secretaria de Meio Ambiente de Guarapuava-PR: qual o grau de conhecimento dos agentes, se há uma consonância entre os setores da autarquia, se as práticas desempenhadas atendem a legislação específica e a sociedade como um todo.

Para tanto, de acordo com o quadro 1, é traçado o perfil da equipe que atua exclusivamente com a gestão de resíduos sólidos no municipio de Guarapuava-PR: 


\begin{tabular}{|c|c|c|c|c|c|c|}
\hline $\begin{array}{l}\text { Nome } \\
\text { Fictício }\end{array}$ & Sexo & Idade & $\begin{array}{c}\text { Formação: } \\
\text { Graduação, } \\
\text { Especialização }\end{array}$ & $\begin{array}{l}\text { Cargo ou } \\
\text { Função }\end{array}$ & $\begin{array}{l}\text { Quantos } \\
\text { anos de } \\
\text { experiência } \\
\text { profissional } \\
\text { na Prefeitura }\end{array}$ & $\begin{array}{l}\text { Quantos } \\
\text { anos } \\
\text { atua com } \\
\text { Gestão de } \\
\text { Resíduos } \\
\text { Sólidos } \\
\text { Urbanos }\end{array}$ \\
\hline $\mathrm{A}$ & Masc. & $\begin{array}{l}\text { Mais de } \\
45 \text { anos }\end{array}$ & $\begin{array}{c}\text { Graduado em } \\
\text { Direito. } \\
\text { Especialista em } \\
\text { Direito Ambiental }\end{array}$ & Secretário & 06 anos & 39 anos \\
\hline B & Fem. & $\begin{array}{l}\text { Mais de } \\
41 \text { anos }\end{array}$ & $\begin{array}{l}\text { Graduado em } \\
\text { Biologia }\end{array}$ & $\begin{array}{c}\text { Bióloga } \\
\text { Educação } \\
\text { Ambiental } \\
\end{array}$ & 14 anos & 06 anos \\
\hline $\mathrm{C}$ & Fem. & $\begin{array}{l}\text { Mais de } \\
45 \text { anos }\end{array}$ & $\begin{array}{l}\text { Graduação (não } \\
\text { informado) } \\
\text { Especialista em } \\
\text { Meio Ambiente e } \\
\text { Cartografia }\end{array}$ & $\begin{array}{l}\text { Coordenadora } \\
\text { de Resíduos } \\
\text { Sólidos }\end{array}$ & 27 anos & 19 anos \\
\hline $\mathrm{D}$ & Masc. & $\begin{array}{c}\text { Não } \\
\text { informado }\end{array}$ & $\begin{array}{c}\text { Graduado em } \\
\text { Engenharia }\end{array}$ & Engenheiro & Não informado & $\begin{array}{c}\text { Não } \\
\text { informado }\end{array}$ \\
\hline $\mathrm{E}$ & Fem. & 30 anos & Ensino Fundamental & $\begin{array}{c}\text { Não } \\
\text { informado }\end{array}$ & Não informado & $\begin{array}{c}\text { Não } \\
\text { informado }\end{array}$ \\
\hline
\end{tabular}

Fonte: A pesquisa.

Após efetivar as entrevistas com a equipe que executa a gestão de resíduos sólidos urbanos no município de Guarapuava, ficou evidente que uma parte conhece a legislação; que atua há alguns anos com o tema; que, em sua formação acadêmica, há uma complementaridade de conteúdo, o que permeia uma gestão heterogênica e sinérgica, culminando em ações pautadas pelo desenvolvimento da região, de maneira sustentável e eficaz.

Todavia, conforme Quental, Lourenço e Silva (2011), para caracterizar a sustentabilidade é necessário entender três aspectos ou propósitos relevantes: economia ecológica, transição de sustentabilidade e a ciência da sustentabilidade. A economia ecológica é amplamente definida como a gestão da sustentabilidade, tendo uma preocupação com a eficiência, justiça e impacto ambiental.Já a transição de sustentabilidade consiste mais num aspecto de revisão histórica sobre a sustentabilidade, uma transição ao longo das primeiras décadas do século XXI. A ciência da sustentabilidade está focada nas interações dinâmicas entre a natureza e a sociedade, com igual atenção para como a mudança social molda o ambiente e como a mudança ambiental molda a sociedade.

Em face da obtenção de dados sobre as quatros dimensões abordadas na pesquisa de campo (ambiental, social, econômica e institucional), acredita-se que a sustentabilidade constitui uma estratégia de desenvolvimento que resulta na melhoria de qualidade de vida humana e na minimização simultânea dos impactos ambientais negativos (MUNCK, et al, 2013). Deste modo, o entrevistado "C" expôs que, atualmente, 120 toneladas de resíduos sólidos urbanos orgânicos são enviadas ao aterro sanitário, e que apenas 4 toneladas de resíduos sólidos urbanos correspondem a reciclados. Desse montante, $2500 \mathrm{~kg}$ são coletados pelos agentes ecológicos e pelos caminhões específicos da coleta seletiva, que faz o trajeto pelos principais bairros da cidade de Guarapuava- 
PR. Nesse quesito, o entrevistado "A" e "B" corroboram o pensamento de que a população ainda não possui atitude de separar os resíduos sólidos urbanos dos orgânicos e não orgânicos/reciclados, pois, se houvesse uma cultura enraizada na sociedade, o volume de reciclados seria muito além do que é coletado diariamente.

Conforme o entrevistado "C", a prefeitura executa o serviço de coleta de resíduos sólidos urbanos, porém a coleta seletiva abrange apenas $58 \%$ da cidade de Guarapuava; entretanto, o município de Guarapuava possui abrangência de 100\% na questão da coleta do resíduo sólido urbano orgânico, no entanto, ressalta-se que não há aproveitamento do material orgânico para compostagem, já que todo o material é destinado ao aterro sanitário, sendo esse com 2.995,25 $\mathrm{m}^{2}$.

Cabe salientar que, de acordo com o entrevistado "D", houve aumento na quantidade de resíduos sólidos urbanos alocados no aterro sanitário, saindo de 19.129,19 toneladas em 2011, para 39.536,39 toneladas em 2017, contudo, o valor de 2017 é ligeiramente menor que 2016, que finalizou em 40.113,51 toneladas. O entrevistado “D” atribui esse aumento significativo, de 78,08 ton/dia em 2011 para 108,32 ton/dia em 2017, com variação média de 5,24\% nos últimos 06 anos, ao aumento do consumo das famílias, a saída de muitas famílias da linha da pobreza e o aumento da renda nos últimos anos. Em contrapartida, criou-se um problema ao município com o tamanho e o peso do aterro sanitário, pois, conforme o entrevistado "D”, o peso do aterro sanitário alcançou o total de 229.824,54 toneladas.

Munck (2014) afirma que enquanto a sustentabilidade refere-se à capacidade de manter algo em um estado contínuo, o desenvolvimento sustentável envolve processos integrativos que buscam manter o balanceamento dinâmico de um sistema complexo em longo prazo. Sob tal aspecto, o entrevistado "C" afirma que há 93(noventa e três) funcionários na coleta do orgânico, 07 (sete) operando no aterro sanitário e 36 funcionários operando na coleta seletiva. O entrevistado "C" ressalta que o aterro é controlado e que não existe a figura do "catador" no aterro sanitário. Dentro dessa dimensão, abordou-se a questão da cooperativa de catadores de material reciclável, sendo que atualmente possuem 180 cooperados e 28 funcionários, e a renda mensal atribuída a esses cooperados varia de $\mathrm{R} \$ 450,00$ a $\mathrm{R} \$ 1.200,00$. Todavia, não há incidência de pessoas com necessidades especiais.

O entrevistado "B" informou que, na cidade, há mais de 400 (quatrocentos) catadores ou operadores ecológicos, mas apenas uma pequena parte é credenciada pela cooperativa. $\mathrm{O}$ entrevistado "B" ressalta que, quando um catador/operador ecológico se credencia à cooperativa, o mesmo recebe um carrinho para o desenvolvimento de sua atividade, além de todo apoio da cooperativa e da Secretaria de Meio Ambiente do município de Guarapuava-PR. Tanto o entrevistado "B" quanto o "C" ressaltam que, o valor do investimento de cada carrinho ultrapassa $\mathrm{R} \$ 3.000,00$ (três mil reais), e que, muitas vezes, esses operadores ecológicos acabam vendendo ou utilizando esse equipamento para outros fins, gerando prejuízo para os cofres públicos.

Tanto o entrevistado "E" quanto o "C" corroboram que é um desafio diário conscientizar esses operadores ecológicos, visto que o grau de escolaridade, cultura, condições básicas de moradia, são sempre escassos e que, muitas vezes, por um "prato de comida" acabam se desfazendo de um bem público.

O entrevistado "A" afirma que por mais que o orçamento da Secretaria do Meio Ambiente seja oriundo de arrecadação do ICMS, Licenças Ambientais e Fundo das Águas (Sanepar), e que 2,73\% do orçamento municipal seja destinado à gestão do resíduos sólidos, é necessário combater 
esse tipo de cultura que onera e prejudica socialmente, ambientalmente e economicamente a sociedade como um todo. Conforme o entrevistado "C", a receita mensal obtida de taxa de lixo, ou outras formas, para a gestão de resíduos sólidos urbanos ultrapassa os $\mathrm{R} \$ 4$ milhões de reais, mesmo assim, o entrevistado "A" afirma que a receita obtida cobre menos de $50 \%$ em relação aos gastos com todo o serviço de manejo, coleta e destino correto dos resíduos sólidos.

Conforme Almada e Borges (2018, p. 434), a sustentabilidade ambiental é contemplada quando todo o processo é entendido, o que inclui funcionários de todos os níveis hierárquicos. As organizações que implementam a estratégia de administração de produtos com o apoio de políticas e práticas de gerenciamento de $\mathrm{RH}$ criam um ambiente orientado para o meio ambiente, o que facilita o caminho para uma vantagem competitiva sustentável.

Dentro desse contexto da dimensão institucional, o entrevistado " $\mathrm{C}$ ” menciona que a capacitação dos funcionários/colaboradores ocorre a cada 03 meses; que há um total de 105 pessoas que trabalham na gestão de resíduos sólidos urbanos e que outras prefeituras procuram a Secretaria do Meio Ambiente de Guarapuava por essa ser referência no modelo de gestão de resíduos sólidos; enfatiza-se ainda que são utilizados diversos meios de comunicação para divulgação e conscientização da coleta seletiva, que existem diversos programas de educação ambiental em escolas, creches e para toda a comunidade, além de desenvolver parcerias com outros entes da sociedade civil organizada.

De fato, as políticas públicas têm sido compreendidas como resultado de um processo decisório em que a alternativa escolhida para a solução de uma questão não se restringe somente ao caráter técnico, mas é fruto de disputas em um contexto institucional, marcado por interesses diversos (ALMEIDA; GOMES, 2018, p. 161-162). Desse modo, com relação à ajuda financeira do governo federal e estadual, o entrevistado "A" menciona:

“não há nenhuma participação financeira do governo federal, já no governo estadual houve apenas ações pontuais, mais precisamente uma única vez, onde o governo estadual auxiliou na compra de equipamentos; todavia, o que dificulta também a gestão de resíduos sólidos urbanos é a dependência de outras secretarias municipais para executar ações importantes no que tange á gestão de resíduos sólidos".

Tal percepção de falta de apoio das esferas federal e estadual também foram citadas pelos demais entrevistados; o entrevistado "B" complementou:

"entre os programas que os mesmos oferecem, há apenas algumas capacitações, sendo estas pontuais, sem recursos. O que a secretaria obteve foi através de projetos pontuais que os governos ofereceram, e o que está secretaria conquistou foi um caminhão para a coleta seletiva, oriundo de recursos do Instituto das Águas.”

Haja vista que há uma política de Gestão de Resíduos Sólidos e ações praticadas pela Secretaria do Meio Ambiente, todos os entrevistados foram unânimes em afirmar que os resultados da gestão de resíduos sólidos só não são melhores, por ainda existir um paradigma na sociedade. O entrevistado "A" afirma que "ainda há falta de cultura da população"; entretanto os entrevistados "B" e "C" naltecem o trabalho realizado até o presente momento e que houve uma melhora significativa por parte da população, contudo há um caminho muito grande a ser percorrido. 
O entrevistado "B" menciona que o grande desafio da gestão de resíduos sólidos no município é a implantação da coleta seletiva em todos os bairros do município, ou seja, atingir a cobertura de $100 \%$. Enquanto isso não ocorrer, ainda será deficitário o plano municipal.

Para melhor entendimento da pesquisa de campo e da análise de resultados referente à identificação das dimensões da TBL proposta Elkington (2012), no quadro abaixo está identificado a percepção individual de cada entrevistado sobre cada dimensão estudada e aplicada ao modelo de Gestão de Resíduos Sólidos na Secretaria de Meio Ambiente do município de Guarapuava-PR.

\section{Quadro 2 - Síntese análise das dimensões da TBL}

\begin{tabular}{|c|c|c|c|c|}
\hline Entrevistado & $\begin{array}{l}\text { Dimensão } \\
\text { Ambiental }\end{array}$ & Dimensão Social & $\begin{array}{c}\text { Dimensão } \\
\text { Econômica }\end{array}$ & $\begin{array}{c}\text { Dimensão } \\
\text { Institucional }\end{array}$ \\
\hline $\begin{array}{c}\text { Entrevistado } \\
\text { "A" }\end{array}$ & $\begin{array}{l}\text { A equipe atua no } \\
\text { atendimento a } \\
\text { política Nacional } \\
\text { do Resíduos } \\
\text { Sólidos - Lei no } \\
\text { 12.305/2010. }\end{array}$ & $\begin{array}{l}\text { Atendimento a } \\
\text { todos os envolvidos } \\
\text { na gestão de } \\
\text { resíduos sólidos, } \\
\text { em especial a } \\
\text { população de baixa } \\
\text { renda - operadores } \\
\text { ecológicos. }\end{array}$ & $\begin{array}{c}\text { A secretaria } \\
\text { possui recursos } \\
\text { suficientes para o } \\
\text { gerenciamento nos } \\
\text { moldes atuais da } \\
\text { gestão de resíduos } \\
\text { sólidos; contudo, } \\
\text { se conseguisse } \\
\text { implementar a } \\
\text { coleta seletiva em } \\
\text { 100\% do município, } \\
\text { seria necessário } \\
\text { remodelar o acesso } \\
\text { a recursos, haja } \\
\text { vista a secretaria e } \\
\text { a Prefeitura receber } \\
\text { recursos pontuais } \\
\text { para a gestão de } \\
\text { resíduos sólidos. }\end{array}$ & $\begin{array}{l}\text { São realizados } \\
\text { esforços } \\
\text { permanentes } \\
\text { para a educação } \\
\text { ambiental, visando } \\
\text { a implementação } \\
\text { da cultura da } \\
\text { sustentabilidade. }\end{array}$ \\
\hline $\begin{array}{c}\text { Entrevistado } \\
\text { "B" }\end{array}$ & $\begin{array}{l}\text { Proteção dos } \\
\text { recursos naturais, } \\
\text { diminuindo } \\
\text { a quantidade } \\
\text { extraída da } \\
\text { natureza, além } \\
\text { de aumentar } \\
\text { a vida útil no } \\
\text { aterro sanitário. }\end{array}$ & $\begin{array}{l}\text { Geração de renda } \\
\text { para a cooperativa, } \\
\text { principalmente } \\
\text { dos operadores } \\
\text { ecológicos. A } \\
\text { cooperativa recebe } \\
\text { todo material } \\
\text { coletado com os } \\
\text { caminhões da } \\
\text { coleta seletiva. }\end{array}$ & $\begin{array}{l}\text { A coleta seletiva } \\
\text { possui uma área } \\
\text { de cobertura de } \\
\text { apenas } 58 \% \text { das } \\
\text { ruas da cidade de } \\
\text { Guarapuava-PR. }\end{array}$ & $\begin{array}{c}\text { São realizadas ações } \\
\text { educacionais com os } \\
\text { servidores, escolas } \\
\text { da rede pública } \\
\text { e privada, além } \\
\text { de treinamento, } \\
\text { divulgação a toda } \\
\text { sociedade. }\end{array}$ \\
\hline $\begin{array}{l}\text { Entrevistado } \\
\text { "C" }\end{array}$ & $\begin{array}{c}\text { Os recursos } \\
\text { são suficientes, } \\
\text { mas busca-se } \\
\text { a ampliação } \\
\text { total da coleta } \\
\text { seletiva. } \\
\text { Diminuição } \\
\text { do impacto no } \\
\text { aterro. }\end{array}$ & $\begin{array}{l}\text { Geração de renda } \\
\text { para as famílias } \\
\text { de operadores } \\
\text { ecológicos. }\end{array}$ & $\begin{array}{c}\text { Através do } \\
\text { programa estadual } \\
\text { Reciclo Paraná, o } \\
\text { governo estadual } \\
\text { dá apoio técnico, } \\
\text { e os recursos } \\
\text { financeiros são } \\
\text { capitaneados pelo } \\
\text { Fundo Municipal } \\
\text { do Meio Ambiente } \\
\text { e pela Prefeitura } \\
\text { Municipal. }\end{array}$ & $\begin{array}{c}\text { É realizado trabalho } \\
\text { de capacitação de } \\
\text { todos os servidores, } \\
\text { demonstrando a } \\
\text { necessidade de } \\
\text { um pensamento } \\
\text { sustentável nas } \\
\text { organizações. }\end{array}$ \\
\hline
\end{tabular}




\begin{tabular}{|c|c|c|c|c|}
\hline Entrevistado & $\begin{array}{l}\text { Dimensão } \\
\text { Ambiental }\end{array}$ & Dimensão Social & $\begin{array}{c}\text { Dimensão } \\
\text { Econômica }\end{array}$ & $\begin{array}{c}\text { Dimensão } \\
\text { Institucional }\end{array}$ \\
\hline $\begin{array}{l}\text { Entrevistado } \\
\text { "D" }\end{array}$ & $\begin{array}{l}\text { Cumprimento } \\
\text { da legislação e } \\
\text { manutenção do } \\
\text { aterro sanitário. }\end{array}$ & Não informou & $\begin{array}{l}\text { A gestão do aterro } \\
\text { sanitário é realizada } \\
\text { pela Prefeitura } \\
\text { Municipal. }\end{array}$ & $\begin{array}{c}\text { Focar na coleta } \\
\text { seletiva com o } \\
\text { intuito de maximizar } \\
\text { e melhorar a gestão } \\
\text { do aterro sanitário. } \\
\text { De } 2016 \text { a } 2017 \text {, a } \\
\text { taxa de variação do } \\
\text { aterro sanitário foi } \\
\text { de }-1,18 \% \text {. }\end{array}$ \\
\hline $\begin{array}{c}\text { Entrevistado } \\
\text { "E" }\end{array}$ & Não informou & $\begin{array}{l}\text { É realizado um } \\
\text { trabalho muito } \\
\text { forte com as } \\
\text { famílias de baixa } \\
\text { renda, com o } \\
\text { intuito de melhorar } \\
\text { a qualidade de vida } \\
\text { delas. }\end{array}$ & $\begin{array}{l}\text { Cada equipamento } \\
\text { concedido ao } \\
\text { operador ecológico } \\
\text { custa em média } \\
\text { R } \$ 3.000,00 \text {, muitas } \\
\text { vezes essas pessoas } \\
\text { carentes acabam } \\
\text { vendendo para } \\
\text { comprar comida, } \\
\text { de fato, esse é } \\
\text { um problema } \\
\text { crônico na gestão, } \\
\text { a falta de cultura } \\
\text { e esses operadores } \\
\text { ecológicos } \\
\text { entenderem que } \\
\text { podem ter uma } \\
\text { renda mensal com } \\
\text { o trabalho efetivo } \\
\text { da coleta seletiva. }\end{array}$ & $\begin{array}{c}\text { É um desafio muito } \\
\text { grande realizar } \\
\text { o processo de } \\
\text { conscientização } \\
\text { dos operadores } \\
\text { ecológicos ou de } \\
\text { famílias de baixa } \\
\text { renda. }\end{array}$ \\
\hline
\end{tabular}

Fonte: a pesquisa.

Conforme as descrições dos entrevistados, juntamente com a interligação da teoria da sustentabilidade, o respectivo trabalho traz contribuições importantes, sendo a principal o início do delineamento de como ocorre a gestão de resíduos sólidos no município de Guarapuava-PR, como os colaboradores estão inseridos nesse contexto e como buscam implementar a visão da sustentabilidade de acordo com o TBL de Elkington (2012), tanto no ambiente organizacional como na sociedade em geral.

De fato, ressalta-se que há unanimidade de todos os entrevistados em relação ao trabalho para mudar um paradigma institucional e cultural de uma sociedade, como se observa no município de Guarapuava-PR, é o grande desafio, até mesmo para se justificar o aumento de orçamento e formas de conscientização. 


\section{Considerações Finais}

Existem vários estudos sobre o desenvolvimento sustentável, a sustentabilidade e a gestão de resíduos sólidos urbanos, entretanto, ao considerar o entendimento de que tanto a organização quanto a Sustentabilidade Organizacional são processos de ações e decisões em constante construção e mutação, é possível afirmar que o desenvolvimento sustentável não deve ser trabalhado como um projeto à parte, demandante de esforços específicos. Pelo contrário, deve integrar os processos organizacionais, tendo os indivíduos como atores centrais nesse caminho (MUNCK, et al, 2013).

O presente trabalho teve como intuito compreender o modelo de gestão de resíduos sólidos urbanos no município de Guarapuava-PR. De fato, averiguou-se que o modelo próprio de gestão atende as demandas previstas na Lei no 12.305/2010 e que são os recursos oriundos do Fundo das Águas (Sanepar), impostos e do Fundo Municipal do Meio Ambiente que subsidiam todas as atividades inerentes à gestão, Todavia, há lacunas a serem preenchidas no município, como o aumento da área coberta da coleta seletiva, acompanhamento mais eficiente dos operadores ecológicos e da indústria/comércio do resíduo sólidos na região, melhor fiscalização dos agentes ecológicos e ações de conscientização da sociedade civil de Guarapuava-PR.

Ao se correlacionar a teoria da sustentabilidade com a gestão ambiental, percebe-se quanto estão interligados e quanto permeiam ações que estão intrinsecamente pautadas na Lei $n^{\circ} 12.305 / 2010$. Dessa forma, pode-se concluir que todos os colaboradores da Secretaria de Meio Ambiente do município de Guarapuava-PR que atuam exclusivamente na Gestão de Resíduos Sólidos Urbanos detêm conhecimento sobre o tema e procuram realizar, praticar, introduzir, instigar o que trata na Lei 12.305/2010. Além disse, estão empenhados em buscar e incrementar ações para a quebra de paradigma da sociedade civil de Guarapuava, com vistas a isso, a educação ambiental é fortemente trabalhada, e uma das formas de quebrar esses paradigmas é atuando com as gerações mais novas.

Para a academia, o tema trabalhado é de suma importância, visto da complexidade do tema, a abordagem teórica e a pesquisa praticada, podendo-se realizar outros estudos sobre a pesquisa efetuada, buscando correlacionar entidades públicas e privadas.

Por fim, sabendo-se da exigência legal sobre a gestão dos resíduos sólidos urbanos, das premissas que norteiam o desenvolvimento sustentável e a sustentabilidade organizacional, principalmente o TBL, o paradigma estrutural da sociedade poderá ser modificado para aumento da eficiência da gestão do Resíduos Sólidos Urbanos.

\section{Referêcias}

ALMADA, L.; BORGES, R. Sustainable Competitive Advantage Needs Green Human Resource Practices:A Framework for Environmental Management.Rio de Janeiro, RAC, v.22, n. 3, art, 6, p. 424-442, 2018.

ALMEIDA, L. A.; GOMES, R. C. Atores, Recursos e Interesses na Formulação da Política Nacional de Resíduos Sólidos. Administração Pública e Gestão Social,v.10, n. 3, p. 161-169, 2018. 
BLOWFIELD, M. Business and Sustainability.Oxford: UK, Learning, 2013.

BRASIL. Lei n. 12.305, de 2 de agosto de 2010: Institui a Política Nacional de Resíduos Sólidos altera a Lei n 9.605, de 12 de fevereiro de 1998; e dá outras providências. Diário Oficial da União, Brasília, DF, 2010.

DENZIN, N. K.; LINCOLN, Y. S. O planejamento da pesquisa qualitativa: Teorias e abordagens. Porto Alegre: 2ed, Artmed, 2006.

DONAIRE, D. Gestão ambiental na empresa. São Paulo: Atlas, 2ed, 2013.

ELKINGTON, J. Canibais com garfo e faca. São Paulo: Makron Books, 2001.

ELKINGTON, J.Canibais com garfo e faca. São Paulo: Makron, 2011.

ELKINGTON, J.Canibais com garfo e faca. São Paulo: Makron, 2012.

FERREIRA, A.Gestão de resíduos sólidos urbanos em municípios do Paraná.Revista Capital Científico - Eletrônica, v.16, n.2, p. 105-119,2018.

GLADWIN, T.N., KENNELLY,J.J.; KRAUSE, T. S. Shifting Paradigms for Sustainable Development.Academy of Management:v.20, n. 4, p. 874-907, 1995.

HART, S. L.; MILSTEIN, M. B. Criando Valor sustentável.RAE Executivo, v. 3, n. 2, p.65-79, 2004.

HOFFMAN, A. J. Climate Change Strategy:The Business Logic Behind Voluntary GreenhouseGas Reductions. California management review:Novembro, 2004.

HOPWOOD, M.; MELLOR, M.; OBRIEN, G. Sustainable Development -Mapping Different Approaches.SustainableDevelopment: v.13, n.1, p. 38-52, 2005.

IBGE - Instituto Brasileiro De Geografia E Estatística. Indicadores de Desenvolvimento Sustentável.Rio de Janeiro,p. 443, 2010.

MUNCK, L ; BANSI, A.C. ; GALLELI-DIAS, B. ; CELLA-DE-OLIVEIRA, F.A. Em busca da sustentabilidade organizacional: a proposição de um framework. Revista Alcance (Online): v. 20, p. 31-46, 2013.

MUNCK, L. Gestão da sustentabilidade nas organizações: um novo agir frente à lógica das competências. São Paulo: Cengage Learning, 2014.

NETO, P.N. Resíduos sólidos urbanos: perspectivas de gestão intermunicipal em regiões metropolitanas. São Paulo: Atlas, 2013.

OLIVEIRA, J. P. S. Análise comparativa da gestão de resíduos sólidos em municípios 
de pequeno porte: estudo de caso. (Dissertação de mestrado). Universidade Estadual Paulista, Bauru, SP, Brasil, 2017.

PRODANOV, C. C. Metodologia do trabalho científico: métodos e técnicas da pesquisa e do trabalho acadêmico [versão eletrônica].Novo Hamburgo: Feevale, 2013.

QUENTAL, N.; LOURENÇO, J. M.; SILVA, F. N. Sustainability: characteristics and scientific roots.EnvironDevSustain: v.13, p. 257-276, 2011.

SACHS, I. Desenvolvimento:includente, sustentável e sustentado. Rio de Janeiro: Gramond, 2008.

SAVITZ, A. W.; WEBER, W. K. Talent, Transformation, and the Triple Bottom Line. San Francisco: Jossey-Bass, 2013.

STEFANO, S. R.; TEIXEIRA, G. Desenvolvimento Sustentável nas Organizações: Programas do Banco do Brasil. Revista Competitividade e Sustentabilidade ComSus,v.1, p. 46-61, 2014.

VEIGA, T. B. Indicadores de sustentabilidade na gestão de resíduos sólidos urbanos e implicações para a saúde humana. (Doutorado em Enfermagem). Universidade de São Paulo: Ribeirão Preto, 2014. 